\title{
The UK is a net exporter of patients
}

\author{
Johanna Hanefeld lecturer, health systems economics ${ }^{1}$, Richard Smith professor and dean of faculty \\ of public health and policy ${ }^{1}$, Neil Lunt senior lecturer in social policy and public sector management ${ }^{2}$, \\ Daniel Horsfall lecturer in comparative social policy ${ }^{2}$
}

${ }^{1}$ London School of Hygiene and Tropical Medicine, London WC1, UK; ${ }^{2}$ University of York, Department of Social Policy and Social Work, York, UK

We have recently completed the most comprehensive research project to date examining the effects of UK medical tourism on the NHS. Research findings currently under review may have some bearing on the debate about the effects of expanding the NHS abroad for UK patients. ${ }^{12}$

Our analysis, which is based on multiple data sources, including the international passenger survey, shows that - contrary to some popular media reports- the UK is a net exporter of patients. More UK residents currently travel abroad for treatment than international patients travel to the UK to access treatment here (in the NHS and privately). Depending on the procedure undertaken, patients who travel abroad may also save the UK resources.

Our research was based on freedom of information requests to NHS foundation trust hospitals. It also found that, despite small numbers of international private patients being treated- $-6 \%$ across a sample of 28 hospitals - these patients were responsible for $35 \%$ of total private income in these trusts. This indicates that private foreign patients may be more lucrative than UK patients treated privately within the NHS.

Overall, as with most discussion of trade in health services, much opinion is based on shaky, if any, evidence. Our study aims to fill that gap, and in doing so shows that many aspects of currently received wisdom are really myths. It shows that we need more accurate evidence to inform policy making on issues discussed by Leonard and Pollock.

Competing interests: None declared.

Pollock AM. Will expansion of the NHS abroad benefit UK patients? No. BMJ 2013;346:e8496. (2 January.)

2 Leonard P. Will expansion of the NHS abroad benefit UK patients? Yes. BMJ 2013;346:e8493. (2 January.) 